\title{
LIVED EXPERIENCES OF THE CHOICE ON TERMINATION OF PREGNANCY ACT 92 OF 1996: BRIDGING THE GAP FOR WOMEN IN NEED
}

\author{
CAMilla Pickles
}

\begin{abstract}
The Choice on Termination of Pregnancy Act 92 of 1996 embodies a laudable and liberal ideal, namely that the course of a woman's life does not have to be determined by her reproductive capacity. Instead, she has the right to free, non-therapeutic termination of pregnancy in a safe environment, a right which exists up to the end of the second trimester. Dignity, equality, and security of the person are therefore the foundation stones of the right. However, this is not the case for women with limited means who have no choice but to rely on the public provision of termination-ofpregnancy services. Studies of women's lived experiences of the implementation of the Act show that there are barriers to accessing termination-of-pregnancy procedures that need to be removed if they are to enjoy this right fully. Not least of these barriers is the state's failure to fulfil its s 27 obligations in terms of the Constitution of the Republic of South Africa, 1996, as well as its far-reaching inaction in engaging with the implementation of the Act. Numerous other barriers exist at the provider and community level. Only through the removal of such barriers and with the state's fulfilment of its obligations will it be possible to translate the provisions of the Act into their envisaged implementation, thus guaranteeing all women in South Africa (regardless of socio-economic standing) the right to safe and quality termination of pregnancy that is accompanied by dignity, equality and security of the person.
\end{abstract}

Key words: abortion, reproductive and sexual rights, health, socio-economic rights, South Africa, women

\section{INTRODUCTION}

In this article, I examine how the Choice on Termination of Pregnancy Act 92 of 1996 (the Choice Act) is experienced by women and service providers in the public sector in order to show that there is a discrepancy between the Act in law and in its clinical implementation. Further, I consider various recommendations with the aim of bridging this gap.

LLD candidate and Academic Assistant at the Centre for Child Law, Department of Private Law, University of Pretoria. This article is based on, and is an adaptation of a paper titled 'Lived Experiences of the Choice on Termination of Pregnancy Act 92 of 1996: Overcoming Obstacles at Ground Level', presented at the conference, Strategies to Overcome Poverty and Inequality: Towards Carnegie III (September 2012), and at the seminar, Poverty and Justice (October 2012). 
The public provision of termination-of-pregnancy (TOP) services is the point of departure, because it can be accepted that, if a woman cannot afford access to the private health-care system, ${ }^{1}$ the public health-care system is the only lawful mechanism available.

In 2008, the World Health Organization (WHO) reported that an estimated 120,000 women in southern Africa had accessed unsafe TOP services, resulting in 500 maternal deaths. ${ }^{2}$ Alarmingly, the report cautioned that these figures should be considered the 'tip of the iceberg', since the incidence of accessing unsafe services, as well as associated mortality rates, tended to be underreported in surveys, and unreported or underreported in hospital records. ${ }^{3}$ These figures therefore indicate that the relevant provisions of the Choice Act are not being fully implemented. Thus, this issue requires closer consideration by moving beyond the detached nature of the law and statistics and examining how the Act is experienced by those people functioning within its reach.

This requires a multidisciplinary approach. Instead of focusing only on how the Choice Act is perceived and applied, I go further and examine a number of publications by the medical profession. In this context, I pay particular attention to recent works that have involved interviewing TOP patients, as well as providers functioning within the sphere of the Choice Act in a hospital or clinic. ${ }^{4}$ It is their voiced experiences that lead to a contextual understanding of the Choice Act. This actual human experience of the Choice Act is something that law-related publications have failed to recognise when analysing the merits of the Act. ${ }^{5}$

In my study, I found that there are systematic failures within the public health-care system. Broadly speaking, these failures are funnelled down to TOP providers and community members as a result of state inaction. Consequently, such failures become access barriers that place numerous women at increased risk, either because they have to terminate their pregnancies later on in the

1 It needs to be mentioned that no information could be sourced on the private provision of TOP services. This makes it impossible to compare the different experiences found in the private and public sectors. However, it was determined that a TOP procedure in the private sector can cost anything from R1,500 to R5,000, depending on how far the pregnancy has progressed and on the method adopted, for example see $<$ http://www.reproductivechoices.co.za/index.php?id=25>; $<$ http://www.drwilliam.za.net/>.

2 WHO 'Unsafe Abortion: Global and Regional Estimates of the Incidence of Unsafe Abortion and Associated Mortality in 2008' (2008) 19, 28. The report defines 'unsafe' TOP as a termination performed by a provider who lacks the necessary skills and qualifications to perform an induced TOP. This definition also includes self-induced TOP. These practices fail to meet officially prescribed circumstances and safeguards.

3 Ibid 15.

4 Consequently, this approach limits the number of studies that can be considered for purposes of this article. Despite being restricted to recent publications on the clinical provision of TOP services, published findings emanating from any recent evaluation of this service are also diminutive.

5 For instance, see L Grelewicz 'Equality and Abortion in Post-Apartheid South Africa: Inspiration for Choice Advocates in the United States' (2011) 13 Oregon Review of Int L 177; C Ngwena 'An Appraisal of Abortion Laws in Southern Africa from a Reproductive Health Rights Perspective' (2004) 32 J of Law, Medicine and Ethics 708. 
gestation period or are obliged to turn to illegal and unsafe TOP providers. In this study, I highlight the fact that these risks are borne by women in need (and some more than others) who cannot afford to access the private health-care system. This gap in meeting the needs of women in the public health-care system as opposed to the private health-care system has very noticeable links to poverty.

\section{Basic Framework of the Choice Act Concerning Access}

On the legislative front, South Africa has a very strong legal framework for accessing TOP services. The preamble of the Choice Act makes specific reference to the furtherance of the values of dignity, the achievement of equality and security of the person. Also, the decision to have children is recognised as being essential to women's physical, psychological and social health. Accordingly, the state is responsible for providing safe reproductive health care for all persons. Further, the right of choice regarding TOP should not be exercised out of fear or harm. ${ }^{6}$

The Choice Act permits TOP on demand in the first trimester, and on socioeconomic grounds in the second trimester. TOP services are more accessible in the first trimester, in that registered midwives and nurses are authorised to perform first-trimester terminations. ${ }^{8}$ Additionally, state policy in the form of the National Health Act 61 of 2003 dictates that TOP services be provided free of charge at public health-care facilities. ${ }^{9}$

To ensure implementation of these provisions, s 10(1)(c) of the Choice Act penalises interference with access to TOP. Thus any person who is found to have prevented a lawful TOP procedure, or to have obstructed access to a TOP facility, is guilty of an offence and liable on conviction to a fine or to imprisonment for a period not exceeding ten years.

These provisions, which have been described as radically liberal, set South Africa apart from other countries in Africa and abroad. ${ }^{10}$ As a result of access to TOP on demand, there has been a substantial decline in TOP-related maternal mortality rates. ${ }^{11}$ In 2011, the Health Systems Trust (HST) reported that 77,780 lawful TOP procedures had been performed. ${ }^{12}$ This was a dramatic increase from 1997, when it was reported that 26,455 lawful TOP procedures had been performed. ${ }^{13}$ However, these figures lose some significance when one realises that an estimated 120,000 women accessed unsafe TOP services

For case law on this subject, see Christian Lawyers Association v Minister of Health 2005 (1) SA 509 (T) 518 (the right of a minor to consent to the termination of her pregnancy). The Transvaal Provincial Division recognised that the right to terminate a pregnancy is in fact a constitutional right which is founded on the right to self-determination.

7 Choice Act s (2)(1)(a) \& (b)(iv) respectively.

8 Choice Act s 2(2).

9 National Health Act s 4(3)(c).

10 Ngwena (note 5 above) 715.

11 R Jewkes \& H Rees 'Dramatic Decline in Abortion Mortality Due to the Choice on Termination of Pregnancy Act' (2005) 95 SAMJ 250.

12 See $<$ http://indicators.hst.org.za/healthstats/47/data $>$.

13 Ibid. 
in 2008, a figure which represents merely a fraction of the problem faced in South Africa. ${ }^{14}$

Charles Ngwena argues that the liberalisation of TOP laws is not always followed by implementation thereof in practice, and that TOP rights may exist merely as rights on paper. ${ }^{15}$ This is certainly the case for those women who cannot afford access to the private health-care sector, and whose experiences are detailed below.

\section{LiVED EXPERIENCES: THE CRACKS APPEAR}

Despite the liberal provisions of the Choice Act, the demand for TOP services is rarely adequately met. ${ }^{16}$ Generally, the public health-care sector is plagued by poor infrastructure, a lack of space within health-care facilities, and the inability to retain staff as TOP providers. ${ }^{17}$ Ultimately, these ill-equipped facilities undermine the availability of safe TOP services. ${ }^{18}$

\section{(a) Experiences of women seeking TOP services}

Studies found that women were attempting to access the health-care system in the first trimester, but that, as a result of delays at various levels, the TOP procedure took place only in the second trimester. ${ }^{19}$

Initially, delays included pregnancy recognition, confirmation and response. ${ }^{20}$ Women recalled signs of pregnancy, but did not link these to a possible pregnancy. ${ }^{21}$ Once the pregnancy was confirmed, women reported experiencing emotional, cultural and religious pressure, and manipulation. ${ }^{22}$ Most women indicated that they were not able to have children owing to varying personal and social circumstances. For instance, they were not ready, did not have the financial means or wanted to continue with schooling. One woman indicated that she was HIV-positive, with limited financial means. ${ }^{23}$ Emotional responses included fear, indecision and conflict, and another woman indicated feeling guilty, since she believed that she would be punished

WHO (note 2 above) 28. The HST (note 12 above) reports that only 75,292 women had access to safe TOP in 2008.

15 C Ngwena 'Using Human Rights to Combat Unsafe Abortion: What Needs to be Done?' (2012) $<$ http://www.chr.up.ac.za/africlaw/charles_ngwenya.pdf $>$.

16 J Harries, N Lince, D Constant, A Hargey \& D Grossman 'The Challenges of Offering Public Second Trimester Abortion Services in South Africa: Health Care Providers' Perspectives' (2012) $44 J$ of Biosocial Science 197.

17 Ibid.

18 Harries et al (note 16 above) 197.

19 J Harries, P Orner, M Gabriel \& E Mitchell 'Delays in Seeking an Abortion until the Second Trimester: A Qualitative Study in South Africa' (2007) 4 Reproductive Health 7, 11.

20 Ibid 9.

21 Harries et al (note 19 above). One participant discussed how she had bought a home pregnancy test and, even after a positive result, had waited another four weeks because she doubted the correctness thereof.

22 Ibid 9; C Bateman 'Abortion Practices Undermining Reformist Laws' (2011) 101 SAMJ 302.

23 Harries et al (note 19 above) 10; J Mendes 'Evaluation of Termination of Pregnancy Services of South Africa' Master of Medicine in Community Health (2011) 109. 
for her decision to terminate her pregnancy. ${ }^{24}$ These responses caused delays in reaching a decision on whether or not to terminate the pregnancy. I submit that these experiences highlight the fact that there is poor provision of reproductive-health counselling, and a general lack of counselling specifically relevant to the TOP procedure.

Further delays were experienced because some women had difficulties in accessing TOP services as a result of provider opposition. ${ }^{25}$ Many women spoke of negative and judgmental attitudes. ${ }^{26}$ Staff were reportedly rude or hostile, and some staff resorted to imposing their religious beliefs on pregnant women by bringing the Bible to consultations. ${ }^{27}$ During a particular consultation, a counsellor reportedly equated TOP with murder. ${ }^{28}$ In another case, a woman described how a relative seeking TOP services was confronted by nurses who explained that she was acting contrary to the rights of the 'baby' and asked her whether her partner was aware that she planned to 'murder' his 'child'. ${ }^{29}$

Opposition also came from support staff (cleaning and administrative staff). A nurse revealed that many members of staff refused to assist, or provide basic care for, TOP patients. ${ }^{30}$ In one instance, an administrative staff member interfered with a woman's access to TOP services by throwing her referral letter way. ${ }^{31}$ Admission clerks have also been reported as refusing to open patient files for women seeking TOP services. ${ }^{32}$

Ineffective referral pathways were also found to cause substantial delays for women attempting to access TOP services. Jewkes et al report that, although women approached the wrong facility for help, they were not referred to the correct facility, and that nurses did not inform them of their rights in terms of the Choice Act. ${ }^{33}$ In some instances, a woman's pregnancy was too far advanced for a particular clinic and she was turned away on these grounds alone, without being referred to the correct facility. ${ }^{34}$

The referral system is worsened by the fact that there is inadequate knowledge of the Choice Act. Jewkes et al report that 54 per cent of the 46 women interviewed did not know about the provisions of the Act, and that 15 per cent did not know which facility offered TOP services. ${ }^{35}$ Research

26 Ibid.

27 Ibid; Mendes (note 23 above) 101.

28 P Orner, M de Bruyn, J Harries \& D Cooper 'A Qualitative Exploration of HIV-positive Pregnant Women's Decision-making Regarding Abortion in Cape Town, South Africa' (2010) 7, 48.

29 R Jewkes, T Gumebe, M Westaway, K Dickson, H Brown \& H Rees 'Why are Women Still Aborting outside Designated Facilities in Metropolitan South Africa?' (2005) 12 BJOG 1236, 1240; Mendes (note 23 above) 101-2.

30 J Harries, K Stinson \& P Orner 'Health Care Providers' Attitudes towards Termination of Pregnancy: A Qualitative Study in South Africa' (2009) 9 BMC Public Health 296.

31 Ibid 299.

32 Harries et al (note 30 above) 299.

33 Bateman (note 22 above) 304; Jewkes et al (note 29 above) 1240.

34 Ibid.

35 Ibid 1240. Also see Mendes (note 23 above) 109. 
indicates that women are aware that they can lawfully terminate a pregnancy, but they lack knowledge of the specific details of the Choice Act, especially with regard to the differences between a first- and second-trimester TOP and the time restrictions involved. ${ }^{36}$

For those women who did find their way to the correct facility, they reported experiencing long waiting periods. In 2006, a study found that it took an average of two-and-a-half visits to health-care facilities before providers initiated the TOP procedure. ${ }^{37}$ This issue is an on going problem. In 2011, Grossman et al reported that women described having had to make three or more visits to clinics before having their pregnancies terminated. ${ }^{38}$ Women have reported delays of up to 30 days occurring between the date of the first visit to the clinic and the date of admission for the TOP procedure. ${ }^{39}$ These delays were the result of clinics being fully booked; hence the women concerned were placed on a waiting list for anything from two to four weeks. ${ }^{40}$ This is particularly problematic for women who are already in the second trimester, especially since no provision is made for the urgency of their situation. ${ }^{41}$

Women have expressed a number of concerns about the TOP procedure. Generally, there is a lack of privacy at public facilities. ${ }^{42}$ In this regard, a doctor has said that women 'hang around in rooms ... waiting and having foetuses between their legs for hours and nobody really cares', but that 'at least it [the procedure] gets done'. ${ }^{44}$ Further, a woman expressed feeling insulted by the lack of care she received after completion of the TOP procedure when she was chased out of the procedure room in order to make space for other TOP patients. ${ }^{45}$ Another woman described how she delivered the products of conception alone in the toilets; afterwards, she was required to 'wrap the whole thing' and proceed to 'go inside for cleaning. ${ }^{46}$ There is moreover a common fear of abuse by nurses and hospital staff. ${ }^{47}$

Another recurring theme relates to stigmatisation of TOP. TOP stigma is described as a compound stigma, in that it builds on other forms of

36 Harries et al (note 19 above) 11; Mendes (note 23 above) 109-10.

37 C Morroni \& J Moodley 'Characteristics of Women Booking for First and Second Trimester Abortions at Public Sector Clinics in Cape Town' (2006) 2 SAJOG 81, 82.

38 D Grossman, D Constant, N Lince, M Alblas, K Blanchard \& J Harries 'Surgical and Medical Second Trimester Abortion in South Africa: A Cross-sectional Study' (2011) 11 BMC Health Services Research 224, 227.

39 Ibid 227.

40 Mendes (note 23 above) 107-8; Harries et al (note 19 above) 11; Jewkes et al (note 29 above) 1240. Also see Orner et al (note 28 above) 47. One woman who was interviewed had falsified her home address, since it was the only way she could obtain TOP services at a facility that did not fall within the jurisdiction of her actual residential area.

41 Jewkes et al (note 29 above) 1240.

42 Ibid.

43 Harries et al (note 30 above) 302.

44 Ibid.

45 Orner et al (note 28 above) 48.

46 Ibid.

47 Ibid. 
discrimination and on structural injustices. ${ }^{48}$ This form of stigma is a social phenomenon that is created, and repeated, locally at various levels (by individuals, communities, institutions, the law and government). ${ }^{49}$ Essentially, it is a negative attribute ascribed to women who terminate their pregnancies that marks them as inferior with regard to the principles of womanhood, since they are seen to be defying long-standing ideals that require subordination to community needs. ${ }^{50}$ TOP is perceived to violate two founding characteristics of female identity: nurturing motherhood and sexual purity. ${ }^{51}$

For instance, in a study conducted by Madu et al, high-school students identified TOP as a taboo theme, that is, as something that one is forbidden to discuss openly, make use of or even consider as a reproductive health-care option. ${ }^{52}$ In this respect, Orner et al found that women were more likely to discuss their positive HIV status with family members and neighbours than discuss their intention to undergo a TOP.$^{53}$ Engaging in the taboo behaviour results in punishment or in feelings of guilt, isolation and degradation. ${ }^{54}$ In some instances, the person engaging in such behaviour is ostracised, because she may lure others into following her example. ${ }^{55}$ As long as TOP is stigmatised, people will be prevented from engaging in open dialogue; hence resultant health consequences (such as unsafe and illegal TOP) cannot be adequately addressed. ${ }^{56}$

Thus far, I have dealt with a number of studies from which a picture emerges of a very intolerant environment. Moreover, studies have found that, based on their previous experiences or general knowledge of the service's reputation, women want to avoid the poor quality of care found at public facilities. ${ }^{57}$ The consequences of being on the receiving end of these services are far-reaching. In some cases, women have been forced to seek help from the private sector, which not only has a financial implication, ${ }^{58}$ but also causes further delay, since they first have to obtain the money. ${ }^{59}$ The problems described above have also been identified as factors encouraging the use of illegal and unsafe TOP services that are known to place women at increased risk. ${ }^{60}$

A Kumar, L Hessini \& E Mitchelle 'Conceptualising Abortion Stigma' (2009) 11 Culture, Health $\&$ Sexuality 625, 634.

49 Ibid 628.

50 Ibid.

51 Kumar et al (note 48 above) 628. Also see A Norris, D Bessett, J Steinberg, M Kavanaugh, S de Zordo \& D Becker 'Abortion Stigma: A Reconceptualization of Constituents, Causes, and Consequences' (2011) 21 WHI 49.

52 S Madu, U Kropiunigg \& M Weckenmann 'Health Complaints of High School Students in the Northern Province and Taboo Themes in their Families' (2002) 22 SAJE 65, 67.

53 Orner et al (note 28 above) 49.

54 Ibid.

55 Madu et al (note 52 above) 65.

56 Ibid.

57 Jewkes et al (note 29 above) 1240.

58 See note 1 above.

59 Mendes (note 23 above) 100-1; Harries et al (note 19 above) 11.

60 Mendes ibid 111; Jewkes et al (note 29 above) 1240. 


\section{(b) TOP providers' experiences and perceptions of TOP patients}

Women's experiences clearly indicate that TOP service delivery is problematic. This thus requires further consideration of the role-players in the provision of TOP services, of the conditions under which these role-players function, and of such role-players' perceptions of women requiring care. Section 2(2) of the Choice Act identifies three role-players in the provision of TOP services, namely registered nurses, registered midwives, and medical practitioners. Registered midwives and nurses ${ }^{61}$ may perform a TOP procedure in the first trimester (up to and including 12 weeks' gestation), and medical practitioners carry out TOP procedures in the second and third trimesters, ie with regard to pregnancies that have developed beyond 12 completed weeks.

A number of studies have highlighted the fact that providers' working conditions make the provision of TOP services very difficult. There is a general lack of human resources and the provision of suitable equipment is inadequate..$^{2}$ Nurses describe TOP services as being overburdened and fragmented, and difficulties are experienced with staff recruitment and retention. $^{63}$ Training is found to be sporadic and is frequently cancelled. ${ }^{64}$ Nurses have furthermore expressed the need for emergency counselling (for difficult TOP cases), since formal counselling occurs only once a month. ${ }^{65}$ Without adequate support, providers feel emotionally unprepared for the experience of being involved in TOP procedures, and are unable to meet the demand. $^{66}$

Nurses report a lack of support from management and colleagues, ${ }^{67}$ which gives rise to feelings of rejection and insufficient appreciation. ${ }^{68}$ In fact, providers report leaving the service because they can no longer endure the negative comments or attitudes of their colleagues. ${ }^{69}$ There is a sense of isolation from the community, and nurses fear victimisation and stigmatisation. ${ }^{70}$ Nurses complain of being labelled as 'serial killers', and of their conduct being described as 'killing children," Doctors who refuse to participate in TOP

61 The terms 'nurse' and 'midwife' will be used interchangeably. Further, the term 'provider' will also be used to refer generally to nurses, midwives and medical practitioners.

62 L Mamabolo \& J Tjallinks 'Experiences of Registered Nurses at one Community Health Centre near Pretoria Providing Termination of Pregnancy Services' (2010) 12 African J of Nursing and Midwifery 73,80 .

63 Harries et al (note 30 above) 302. A nurse reported that, at her facility, only a certain number of women could be helped a day, because there were not enough staff available to meet the demand.

64 Ibid 301. Also see Mendes (note 23 above) 111, who reports high complication rates linked to TOP procedures and attributes these occurrences to overburdened work conditions.

65 Mamabolo \& Tjallinks (note 62 above) 81.

66 P Mayers, B Parkes, B Green \& J Turner 'Experiences of Registered Midwives Assisting with Termination of Pregnancies at a Tertiary Level Hospital' (2005) 10 Health SA 15, 19.

67 Ibid 23.

68 Mamabolo \& Tjallinks (note 62 above) 81.

69 Harries et al (note 30 above) 301; Bateman (note 22 above) 304.

70 Ibid.

71 Mamabolo \& Tjallinks (note 62 above) 79. 
procedures face being labelled as uncooperative and lazy, and fear not being considered for speciality posts in obstetrics and gynaecology. ${ }^{72}$

Studies have found that some providers participate in the provision of TOP services despite having personal reservations about TOP. Others choose to do so because they believe that they have a responsibility to their community to provide safe TOP services. ${ }^{73}$ However, those who compromise their personal value system report experiencing discomfort and difficulty with the compromise. ${ }^{74}$ Doctors, for instance, described experiencing short-term feelings of anxiety, guilt, depression, tension and trauma. ${ }^{75}$

Research also demonstrates that providers strongly oppose secondtrimester TOP procedures. These procedures are described as traumatic, because, at this stage of development, the foetus begins to resemble a human being, and, once delivered, may still move about even though it is not viable. ${ }^{76}$ The second-trimester TOP procedure of dilatation and evacuation elicits more physical and emotional responses from providers, since staff members are exposed to the aborted foetus. ${ }^{77}$ These situations introduce a conflict between life and death, because providers are being confronted with life where death is anticipated. ${ }^{78}$ This is said to place an enormous ethical burden on providers, because they pledge to preserve life. ${ }^{79}$

Providers' perceptions of women also impact on the quality of their service delivery. Nurses reportedly expected patients to display feelings of sadness and loss. When this did not occur, patients were perceived as being indifferent to the significance of TOP $^{80}$ Nurses furthermore described patients as 'demanding' and 'seeking attention'. ${ }^{, 1}$ In this context, patients were perceived to have little regard for how staff felt when having to provide this type of service. $^{82}$

Midwives also reported experiencing difficulty in dealing with the apparent lack of responsibility shown by some patients who refused to consider contraception, ${ }^{83}$ such as teenage patients ${ }^{84}$ and those women 'suspected'

P Caldas da Costa \& F Donald 'The Experience of Person-Role Conflict in Doctors Expected to Terminate Pregnancies in South African Public Sector' (2003) 33 SA J of Psychology 10, 14.

73 Ibid 13.

74 Caldas da Costa \& Donald (note 72 above) 15.

75 Ibid.

76 Harries et al (note 30 above) 301; Caldas da Costa \& Donald (note 72 above) 15.

77 Harries et al (note 16 above) 201. However, the only alternative method available is medical induction (the use of prescribed medication). This takes up bed space and requires a stay in hospital, since it takes roughly 24 hours to terminate the pregnancy and deliver the products of conception, see Harries et al (note 16 above) 202.

78 Mayers et al (note 66 above) 21.

79 Ibid 22; Caldas da Costa \& Donald (note 72 above) 13.

80 Mayers et al (note 66 above) 19.

81 Ibid.

82 Ibid.

83 Ibid.

84 Ibid 22. 
of 'repeat abortionss. ${ }^{85}$ It was found that women who used TOP services repeatedly were perceived to be using this service as a contraceptive method and were considered sexually promiscuous and irresponsible. ${ }^{86}$ Here, one can see the manifestations of TOP-related stigma taking hold in the provision of TOP services.

Nurses moreover believed that patients' fear of the unknown, in addition to inadequate preparation for the procedure, caused the patients to be obnoxious and rude to staff. ${ }^{87}$ These negative responses by patients were found to lead to their physical and mental isolation by attending midwives. ${ }^{88}$ Clearly, adequate counselling would remedy these negative perceptions. However, the need to counsel a patient was seen as burdensome, and the provision of emotional support was believed to fall beyond the scope of the midwives' employment. ${ }^{89}$ Those who did recognise the importance of counselling, asserted that it was difficult to provide the service, because providers were overburdened with the general demands stemming from TOP procedures. ${ }^{90}$

Conversely, providers were found to be more willing to assist in cases where the pregnancy was a result of rape, incest or foetal abnormality. ${ }^{91}$ Further, socio-economic reasons seemed to elicit sympathy for patients. ${ }^{92}$ However, other nurses were of the opinion that non-therapeutic TOP on demand was an unacceptable practice. ${ }^{93}$

In response to these work conditions, providers developed coping mechanisms that involved physical and emotional detachment. Providers thus considered TOP as merely being part of the job. ${ }^{94}$ They viewed themselves as 'technicians' equipped with the expertise to provide TOP services, but did not consider themselves responsible for the decision reached by the patient. ${ }^{95}$ I submit that this approach is problematic, because a TOP procedure is not merely mechanical in nature. The procedure involves, and is performed on, an individual human being who has to physically and emotionally experience the reception of this service.

Providers' work conditions and personal perceptions have a direct influence on the quality of TOP services women receive. The structural obstacles described by providers were found to influence the quality of care provided, as well as the ability of providers to cope with the situations they faced. ${ }^{96}$

Harries et al (note 30 above) 301. It must be noted that Harries et al do not refer to documented evidence of women repeatedly accessing TOP services in the facilities where providers were being interviewed. It is therefore not clear whether the issue of 'repeat abortions' is as extensive as it is perceived to be.

86 Ibid.

87 Mayers et al (note 66 above) 19.

88 Ibid.

89 Ibid.

90 Harries et al (note 30 above) 301.

91 Ibid 300.

92 Ibid 301.

93 Ibid.

94 Mayers et al (note 66 above) 22.

95 Caldas da Costa \& Donald (note 72 above) 13.

96 Mayers et al (note 66 above) 19. 
As a result of acting contrary to personal belief systems, providers reported negative attitudes to women, showed less patience with, and compassion for, TOP patients, and devoted less attention and time to them. ${ }^{97}$ Nurses reported feelings of frustration and stress, particularly when the TOP procedure took longer than expected or when women displayed a negative emotional response to the procedure. ${ }^{98}$

To sum up, the picture projected by the Choice Act is, for the purpose of this analysis, far from the reality some women face when accessing, or attempting to access, safe and lawful public TOP services. Shortcomings in the system are hushed, the system is shaped by negative personal and community perceptions, there is systemic stigmatisation, and the service is completely overburdened. The system is best described as a festering environment. In view of this, it is clear that the rights of those women who cannot afford private TOP services are not being fulfilled in terms of the Choice Act. Essentially, there is a failure to realise substantive equality for these women. ${ }^{99}$ Where the drive to unburden themselves of unwanted pregnancies is strong enough, women may have no choice but to turn to illegal and unsafe TOP services.

\section{The Constitution and the State's Role in the Provision of Top SERVICES}

Section 27(1)(a) of the Constitution of the Republic of South Africa, 1996, provides that everyone has the right to access health-care services, including reproductive health care. However, this right does not embrace individual entitlement to the immediate provision of any service or resource. ${ }^{100}$ Section 27(2) obliges the state to take reasonable legislative and other measures, within its available resources, to achieve the progressive realisation of the right. This places a positive obligation on the state to formulate a comprehensive and workable plan to meet its obligations to progressively realise socio-economic rights within available resources. ${ }^{101}$

In Soobramoney v Minister of Health, ${ }^{102}$ the Constitutional Court held that the obligations imposed on the state to progressively realise socio-economic rights are dependent upon the resources available for such purposes, and that socio-economic rights will therefore be limited by reason of a lack of resources. In Government of the Republic of South Africa v Grootboom, the Constitutional Court held that this limitation means that both the content of

Ibid.

98 Mamabolo \& Tjallinks (note 62 above) 79.

99 In this respect, see, R Rebouché 'The Limits of Reproductive Rights in Improving Women's Health' (2011) 63 Alabama LR 1. In line with the theme of this article, Rebouche asserts that if we fail to respond to the particularities of our health-care system or our social context, adequate implementation of laws cannot be addressed.

100 D Bilchitz 'Health' in S Woolman et al (eds) Constitutional Law of South Africa 2 ed (2012) (revision service 4 volume 4) 56A-1.

101 Government of the Republic of South Africa v Grootboom 2001 (1) SA 46 (CC) para 39 (constitutional right to housing).

1021998 (1) SA 765 (CC) para 11 (constitutional right to access emergency medical treatment). 
the obligation in relation to the rate at which realisation of rights is achieved and the reasonableness of the measures employed to achieve the result, are governed by availability of resources. ${ }^{103}$

Bilchitz states that socio-economic rights require the state to develop a systematic and comprehensive programme that is designed to realise these rights progressively. ${ }^{104}$ Grootboom found that progressive realisation means that 'accessibility should be progressively facilitated: legal, administrative, operational and financial hurdles should be examined and, where possible, lowered over time'. ${ }^{105}$

Whether the state has discharged its duty to progressively realise any particular socio-economic right will be evaluated by the courts in terms of the 'reasonableness' of the programme concerned. ${ }^{106}$ This requires a contextual evaluation of the circumstances. ${ }^{107}$ In Mazibuko v City of Johannesburg, ${ }^{108}$ the Constitutional Court held that the positive obligations imposed on government will be enforced by courts in at least two of the following instances: if government takes no steps at all to realise rights or where government adopts measures that are unreasonable. In the latter case, the court will require that the measures adopted, be revised. ${ }^{109}$ The court then identified three instances of unreasonableness: where the adopted measures make no provision for those in desperate need; where the government adopts a policy with unreasonable exclusions or limitations; or where government fails to continually review its policies to ensure that the achievement of socio-economic rights is progressively realised. ${ }^{110}$

Concerning the third example of unreasonableness, the court in Grootboom found that legislative measures on their own are not enough to constitute constitutional compliance with s 27 obligations. ${ }^{111}$ The state is obliged to act to achieve the intended result. Therefore legislative measures must be supported by appropriate, well-directed policies and programmes. ${ }^{112}$ These policies and programmes must also be reasonably implemented. ${ }^{113}$ Further, the state must

103 Para 46. The criteria developed in Soobramoney ibid and Grootboom (note 101 above) were also applied by the Constitutional Court in Minister of Health v Treatment Action Campaign 2002 (5) SA 721 (CC) (constitutional right to access an antiretroviral drug within the public health-care sector).

104 Bilchitz (note 100 above) 56A-2.

105 Para 45.

106 Grootboom (note 101 above) para 42.

107 Bilchitz (note 100 above) 56A-2. Bilchitz identifies criteria previously used by the Constitutional Court when evaluating a state programme, namely: the programme must ensure that appropriate financial and human resources are available; it must be capable of facilitating the realisation of the right concerned; it must be flexible and attend to a 'crisis'; it must not exclude a significant segment of the affected population; and it must balance short-, medium- and long-term needs.

1082010 (4) SA 1 (CC) para 67 (constitutional right to access sufficient water).

109 Ibid.

110 Mazibuko (note 108 above) para 67.

111 Grootboom (note 101 above) para 42.

112 Ibid.

113 Ibid para 42 
be aware that conditions do not remain static and that devised programmes and policies require continual review. ${ }^{114}$

With regard to the implementation of the Choice Act, it is clear that the state, through legislation and policy, has responded systematically to the pressing social need to curb unwanted pregnancies, and has consequently reduced maternal morbidity and mortality rates linked to unsafe and illegal TOP. The Choice Act is applied throughout South Africa, TOP services are available during the first and second trimesters, and such services are provided free of charge at public health-care facilities for women of all ages. ${ }^{115}$ However, there is still a missing link between the Choice Act and women in need, because, in 2008, an estimated 120,000 women accessed illegal and unsafe TOP procedures, while, in that same year, only 75,292 women had access to legal and safe services, ${ }^{116}$ which is a substantial discrepancy. With such liberal provisions in place, illegal TOP providers should not be thriving; in fact, there should be no need for them at all.

The experiences described in the studies dealt with above mirror the contents of a study commissioned by the Department of Health of the Republic of South Africa, which was released in $2000 .^{117}$ The study highlighted the very same complaints: long waiting lists, poor understanding of the provisions of the Choice Act, negative staff attitudes, a lack of resources, and women's willingness to access unsafe and illegal TOP service providers as opposed to lawful services.

The study made a number of recommendations. Concerning increased access to TOP services, the report recommended that norms pertaining to service provision for first- and second-trimester TOP be established for all provinces. ${ }^{118}$ These, stated the report, should include the number of services to be provided, based on the proportion of the female population of reproductive age living within a certain distance of the respective services, as well as the capacity of the services, which should be determined by the average number of TOP procedures performed per month per 100,000 women. ${ }^{119}$ The report further recommended that there should be annual monitoring of each

114 Ibid para 43; Mazibuko (note 108 above) para 40. For a critical review of the Constitutional Court's approach to adjudicating socio-economic rights disputes, see D Brand 'Judicial Deference and Democracy in Socio-economic Rights in South Africa' (2011) 3 Stellenbosch LR 614; G Quinot \& S Liebenberg 'Narrowing the Band: Reasonableness Review in Administrative Justice and Socio-economic Rights Jurisprudence in South Africa' (2011) 3 Stellenbosch LR 639; S Wilson \& J Dugard 'Taking Poverty Seriously: The South African Constitutional Court and Socio-economic Rights' (2011) 3 Stellenbosch LR 664; M Pieterse 'Legislative and Executive Translation of the Right to Have Access to Health Care Services' (2010) 14 Law, Democracy \& Development 1 .

115 See, generally, Department of Health of the Republic of South Africa 'Guidelines for Maternity Care in South Africa' (2007) 7 <http://www.doh.gov.za/docs/policy/2011/guidelines_a.pdf>.

116 WHO (note 2 above) 19; HST (note 12 above). Beyond 2008, there are no known estimated figures for women who have accessed unsafe and illegal TOP services.

117 Department of Health of the Republic of South Africa 'An Evaluation of the Implementation of the Choice on Termination of Pregnancy Act' (2000).

118 Ibid 37.

119 Ibid. 
province in terms of meeting the norms for the provision of TOP services. ${ }^{120}$ Plans should also be developed to enhance the provision of TOP services, including training providers, at primary-care level. ${ }^{121}$ Moreover, provinces should develop plans for improving services, based on an understanding of local circumstances and barriers. ${ }^{122}$

On the issue of unsafe and illegal TOP, the report recommended that further efforts needed to be made to meet the then unmet demand for legal TOP services. ${ }^{123}$ It was found that this could be achieved through improving accessibility by enhancing service delivery in underserviced areas, launching public information campaigns on TOP rights, and increasing awareness of the Choice Act. ${ }^{124}$ It was also recommended that the quality of care in the public health-care sector needed to be improved so that women could access TOP services without fear of harassment by staff. ${ }^{125}$ Further, safe involvement of general practitioners should be encouraged. ${ }^{126}$ Lastly, it was advised that public education regarding emergency contraception should be undertaken and that the availability of such contraception be ensured. ${ }^{127}$

Twelve years on, not much else can be found concerning reported state involvement in initiatives for the effective implementation of the Choice Act. It is not clear whether provinces have followed through with the recommendations of the study, and nothing can be found concerning annual evaluations of the performance of each province in the provision of TOP services. ${ }^{128}$ Perusal of the official websites of national and provincial departments of health reveals that no new studies have been completed on TOP services, even though the same complaints are being made year after year. ${ }^{129}$ In the KwaZulu-Natal Department of Health Strategic Plan 2010-2014, it is indicated that, from 2008 to $2009,12,528$ TOP procedures were performed, compared with 14,435 from 2007 to $2008 .^{130}$ During the period 2008 to 2009,305 septic TOP procedures and 11,343 incomplete TOP procedures were reported, leading the provincial department of health to concede that services to prevent unwanted pregnancies were inadequate. ${ }^{131}$ However, the report failed to consider any remedial steps.

123 Department of Health (note 117 above) 71

124 Ibid.

125 Ibid 97

126 Ibid.

127 Ibid.

128 In this regard, the official website of each province's health department was searched with the aim of finding official reports on the topic of TOP.

129 The Free State released a quarterly report on TOP for April-June in 2006. However, this report does not consider access barriers. Free State Department of Health 'TOP Report' (2006) $<$ http://www.fshealth.gov.za/portal/page/portal/fshp/DOCUMENTS/corporate/reports/top/all/ TOP\%20Report\%20April\%20to\%20June\%202006.pdf>.

130 KwaZulu-Natal Department of Health 'Strategic Plan 2010-2014' (2010) <www.kznhealth.gov. $\mathrm{za} /$ stratplan2010-14.pdf $>$.

131 Ibid 79. 
Marius Pieterse argues that legislative and executive translation of s 27 rights into real lived experiences is incomplete. ${ }^{132} \mathrm{He}$ argues that logistical factors, such as those experiences described earlier in this article, are the result of legislation or policy having failed to define, adequately, the scope of obligations incurred by obligation bearers. He further argues that there must be increased translation of horizontal obligations incurred in terms of socioeconomic rights. ${ }^{133}$ In this regard, he refers to a number of issues emanating from the Choice Act, namely the fact that the Act limits nurses' and midwives' roles to terminating only first-trimester pregnancies, and that it is silent on the matter of a provider's right to conscientious objection. ${ }^{134}$ Consequently, access to care in the context of TOP services is haphazardly and inconsistently implemented because of obscurity, vagueness or inherent contradictions concerning entitlements or obligations. ${ }^{135}$ The incomplete realisation of rights leads to a lack of awareness of any obligations; or to unwillingness on the part of obligation bearers to comply with these obligations; or enables obligation holders to deny enforceability of obligations; or creates space for a discretion that leads to inconsistent and unequal implementation of the Choice Act. ${ }^{136}$ This all occurs at the expense of women in need, who have no choice but to rely on public provision of TOP services.

The lack of frequent, visible and meaningful interaction by the national and provincial departments of health with the implementation of the Choice Act is worrisome and leads one to question whether the state is adequately meeting its constitutional obligations in terms of s 27 of the Constitution. The state is required to progressively lower barriers (administrative and operational) to accessing TOP services. However, this cannot be achieved without regular review of the state's current policy concerning the free provision of TOP services. Without an adequate understanding of the lived experiences of women and TOP providers, the state is ill equipped to implement any meaningful reforms.

\section{Recommendations to Include in a TOP Policy Review}

With the aim of making TOP services more accessible in the public sector, I shall consider numerous recommendations that stem from clinical experiences of the Choice Act. This is done in the hope that the state will, when reviewing the current TOP policy, take these recommendations into account and develop a revised policy that reflects these lived experiences.

Women and girls accessing the service, and the wider community, need to be actively engaged in education campaigns concerning reproduction, early

132 Pieterse (note 114 above) 17.

133 Ibid 16.

134 Ibid.

135 Ibid 15 .

136 Ibid 17; Bateman (note 22 above) 304. 
pregnancy recognition and the Choice Act. ${ }^{137}$ Orner et al point out that medical and surgical TOP procedures need to be properly explained to women, as this will help reduce the confusion and anxiety that women experience. ${ }^{138} \mathrm{I}$ submit that, without this information, it cannot be accepted that these women or girls have reached an informed decision concerning the termination of their pregnancies. ${ }^{139}$

It has been suggested that, rather than expanding TOP services, there needs to be an increased focus on broader reproductive-health services, especially contraceptive services. ${ }^{140}$ It is argued that this will assist in reducing the overall demand for TOP services. Harries et al identify a number of barriers to accessing contraceptive services, including women being offered a limited choice of contraceptives, the overemphasis of condoms, little or no pre- or post-TOP counselling, and general problems in accessing family-planning clinics. ${ }^{141}$ Problems in accessing family-planning clinics are due, among other things, to restricted operating hours, and contraceptive services are not always available at the site of TOP services. ${ }^{142}$ As a result of this fragmented system, women are at times required to take a number of days' leave from work in order to receive contraceptive counselling after the TOP procedure. ${ }^{143}$

Some providers recommend developing dedicated centres for TOP services in order to create a more supportive environment for patients and staff. ${ }^{144}$ It has been suggested that this may offer a solution to the negative attitudes of health-care providers and support staff. A more supportive environment could have the added benefit of retaining trained providers, ${ }^{145}$ since the clinic would be staffed by people who choose to work in that specific area of health care instead of general gynaecology. ${ }^{146}$

Harries et al argue that current TOP procedures should be reconsidered in order to allow same-day TOP procedures, which is the present practice

137 F Lang, G Joubert \& E Prinsloo 'Is Pregnancy Termination Being Used as a Family Planning Method in the Free State?' (2005) 47 SA Family Practice 52, 55; Morroni \& Moodley (note 37 above) 82 .

138 Orner et al (note 28 above) 50.

139 For a comprehensive description of the doctrine of informed consent, see P Carstens \& D Pearmain Foundational Principles of South African Medical Law (2007) 875-93. The doctrine of informed consent in the context of TOP procedures was dealt with in Christian Lawyers Association (note 6 above) 515-6 where the court stated that informed consent consists of three elements: knowledge, appreciation and consent. 'Knowledge' requires a woman to be aware of the nature and extent of the risk; 'appreciation' requires a woman to understand the extent of the risk inherent in termination procedures; and 'consent' means that a woman must subjectively consent to the risk, and that her consent must be comprehensive to the extent that she consents to the entire transaction, inclusive of all its consequences.

140 Harries et al (note 16 above) 204.

141 Ibid.

142 Ibid.

143 Ibid.

144 Harries et al (note 30 above) 302.

145 Ibid 303.

146 Jewkes et al (note 29 above) 1241. However, see Norris et al (note 51 above) 51 who state that this approach has been adopted in the United States, but has led to the isolation of these clinics from mainstream health care, as well as to the marginalisation of TOP procedures and of those who provide the service. 
in private facilities. In a study conducted by Harries et al, they found that a second-trimester medical TOP (intake of Misoprostol) was a lengthier termination process than a surgical TOP procedure (dilation and extraction), and consequently required longer hospitalisation in a bed-restricted environment. ${ }^{147}$ However, they concede that a combination of Mifepristone and Misoprostol ${ }^{148}$ would have good results in a medical TOP. ${ }^{149}$ Although Mifepristone is more expensive, it may still be cost-effective since it has been found to reduce the duration of hospitalisation owing to the quicker TOP procedure. Harries et al further argue that introducing a low-cost Mifepristone product into health-care facilities that do not have trained or willing surgical TOP providers might significantly improve the capacity of TOP services to meet the demands of women. ${ }^{150}$ The benefit of this method is that the TOP procedure can be completed in a day. ${ }^{151}$

The demand for second-trimester TOP must be curbed. Grossman et al state that every additional week of gestation significantly increases the risk of mortality. ${ }^{152}$ Furthermore, a second-trimester TOP is costly to the healthcare system. The risks associated with a second-trimester TOP lead to an increased demand being placed on already scarce resources and require substantial investment in training, ${ }^{153}$ particularly because the procedure must be performed or prescribed by a medical practitioner. General provider opposition to a second-trimester TOP requires that the need for this service be minimised. $^{154}$

In this respect, it is critical that referral processes be improved in order to minimise delays in accessing TOP services. ${ }^{155}$ Morroni and Moodley recommend greater access to urine pregnancy testing at public-sector clinics. ${ }^{156}$ They report that the timing of presentation for pregnancy-related treatment (antenatal care or TOP) is influenced by access to urine pregnancy testing. ${ }^{157}$ Consequently, access to urine pregnancy testing has the potential to curb the demand for second-trimester TOPs. ${ }^{158}$ In cases where women do present for TOP services in the second trimester, Jewkes et al recommend that they be given priority, since any further delay will result in them being denied access to lawful and safe TOP services owing to advanced pregnancy. ${ }^{159}$

147 Harries et al (note 16 above) 205.

148 These medications are only indicated for first-trimester TOP procedures. It is standard procedure that Misoprostol be used on its own in the first trimester.

149 Also see Bateman (note 22 above) 302-4.

150 Harries et al (note 16 above) 206.

151 Ibid. The authors state that this depends on whether a pharmaceutical company will attempt to register Mifepristone for use in second-trimester TOP procedures or if the Department of Health will allow widespread off-label use of the product.

152 Grossman et al (note 38 above) 229.

153 Ibid 231.

154 Harries et al (note 18 above) 14.

155 Grossman et al (note 38 above) 229.

156 Morroni \& Moodley (note 37 above) 26.

157 Ibid 29.

158 Ibid.

159 Jewkes et al (note 29 above) 1241. 
One of the most important recommendations to emerge from the study of clinical experiences relates to the use of values-clarification workshops. ${ }^{160}$ As with the wider community, there is a need in the medical field to remove the stigma associated with TOP. Women accessing TOP services, and TOP providers, are the victims of 'abortion stigma', and this is exceedingly detrimental to the provision of TOP services. ${ }^{161}$ Harries et al state that valuesclarification workshops are designed to convey the patients' perspective and can improve providers' perceptions of women accessing TOP services. ${ }^{162}$ Further, values clarification and client-centred training may also increase providers' emotional support for patients. ${ }^{163}$

Mitchell et al state that the purpose of values-clarification workshops is not to change opinions immediately, but to inform participants and help build tolerance. ${ }^{164}$ The workshops therefore allow health-care providers an opportunity to clarify their values and attitudes and to bring about changes in their attitudes and behaviour towards women accessing the service. ${ }^{165}$ Harries et al recommend the use of values-clarification workshops for TOP providers and all health-care providers in the areas of reproductive health. ${ }^{166}$ Mitchell et $\mathrm{al}^{167}$ report on a study of values-clarification workshops that also included traditional leaders, traditional healers, ${ }^{168}$ members of faith-based organisations, and municipal councillors, since these stakeholders play a leading role within the community.

Some providers indicate that values-clarification workshops have helped them define their role as facilitators who guide rather than direct women. ${ }^{169}$ Mitchell et al report that, as a consequence of values-clarification workshops, attendees have begun to engage in 'new activities' that range from diverse forms of advocacy and personal effort so as to enhance the quality and reach of reproductive health care. ${ }^{170}$ For instance, there are community-oriented initiatives that focus on disseminating information or providing support for

160 See, generally, K Turner, A Hyman \& M Gabriel 'Clarifying Values and Transforming Attitudes to Improve Access to Second Trimester Abortion: Women's Health and Public Policy’ (2008) 16 Reproductive Health Matters 108. Although the authors mention that this aspect of TOP requires further research, they are confident of its potential value in improving service provision.

161 Norris et al (note 51 above) 49; Kumar et al (note 48 above) 625.

162 Harries et al (note 16 above) 205.

163 Ibid.

164 E Mitchell, K Trueman, M Gabriel, A Fine \& N Manentsa 'Accelerating the Pace of Progress in South Africa: An Evaluation of the Impact of Values Clarification Workshops on Termination of Pregnancy Access in Limpopo Province' (2005) $10<$ http://www.ipas.org/ /media/Files/ Ipas\%20Publications/SAvcEval.ashx>.

165 Harries et al (note 30 above) 302.

166 Harries et al (note 19 above) 12.

167 Mitchell et al (note 164 above) 13.

168 The inclusion of traditional healers is extremely important in a South African context, because Jewkes et al (note 29 above) 1238 report that consulting with a traditional healer to terminate a pregnancy is a 'normal' response and that traditional healers are generally the first healthcare choice for many South Africans. This argument is supported by the South Human Rights Commission Public Inquiry Access to Health Care Services (2008) 20, which indicates that an estimated 70 per cent of the South African population consult with traditional health practitioners.

169 Harries et al (note 30 above) 302.

170 Mitchell et al (note 164 above) 29. 
facilities. ${ }^{171}$ Health-care providers also report that they are making incremental improvements in the quality and extent of services. ${ }^{172}$ Thus, for example, a new ward has been created for the provision of TOP services, while others report that they are allocating more staff or are increasing the designated number of beds for TOP patients. ${ }^{173}$ In addition, several health-care providers and community leaders report that they have begun providing individual patient counselling. ${ }^{174}$ Collectively, an effort has been made to meet with and positively influence non-attending health professionals regarding their approach to, and provision of, TOP services. ${ }^{175}$ Further, a religious leader has reported that his church holds regular youth rallies to speak about TOP services, since the church council is supportive of spreading the message of accessing safe TOP services. ${ }^{176}$ Changes at health-facility levels have also been identified, in that staff have demonstrated a positive change in attitude to TOP, service providers and the women using the service. ${ }^{177}$ It has furthermore been reported that health-care providers are experiencing enhanced communication among themselves, and between themselves and TOP patients, enabling everyone to talk freely about TOP procedures. ${ }^{178}$

In order to develop a positive attitude to TOP generally, Cheryl Potgieter and Gail Andrews identify a number of valuable aspects that should be included in the material for values-clarification workshops. ${ }^{179}$ Knowledge about the impact of unsafe TOP procedures on women's mortality and morbidity needs to be developed. ${ }^{180}$ When engaged in an education programme, it is necessary to work though judgmental attitudes to TOP services. ${ }^{181}$ People should be encouraged to adopt a flexible and broad interpretation of religion and culture, and to recognise that one person's interpretation of an aspect of religion may be different from their own. ${ }^{182}$ Those who are directly or indirectly involved in the provision of TOP services must develop a good sense of their role as active citizens, and must view a woman's right to control her body as a fundamental right. ${ }^{183}$ Potgieter and Andrews also argue that people's attitudes on certain issues may change as a result of personal experiences, such as interacting with others who hold different opinions. ${ }^{184}$ They therefore suggest providing a

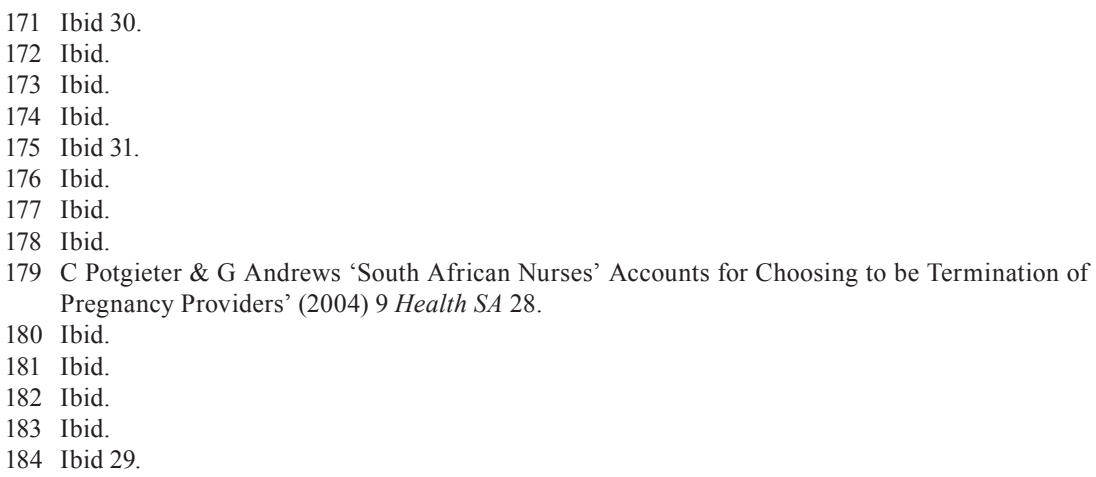


non-threatening environment in which different opinions on the topic can be shared. ${ }^{185}$

Values-clarification workshops may also provide a platform for providers to work through their experiences as TOP providers. If their issues are properly addressed and acknowledged, they will be in a better position to perform according to the required professional standard. ${ }^{186}$

A number of experiences described by women may constitute criminal offences in terms of s 10(1)(c) of the Choice Act. ${ }^{187}$ Although these provisions could play a valuable role in the overall implementation of the Choice Act, it is recommended that this avenue not be explored within the context of this topic. An all-inclusive approach is suggested where the concerns of all parties are considered in order to advance the needs of women and girls trying to access TOP services. If criminal sanctions are used as the starting point, we may lose the much-needed support of the health-care system.

\section{CONCLUding Remarks}

The Choice Act embodies a laudable and liberal ideal, namely that the course of a woman's or girl's life does not have to be determined by her reproductive capacity. Instead, she has the right to free, non-therapeutic TOP in a safe environment, a right which exists up to the end of the second trimester. Anyone found interfering with this right, faces criminal prosecution. Dignity, equality, and security of the person are therefore the foundation stones of the right.

Notwithstanding this, effective translation of the ideal into actual lived experiences is lacking, particularly in respect of women with limited financial means. Despite a demonstrable increase in the provision of TOP services, there is still a large group of women who are excluded from the benefits of the Choice Act. Women's experiences and perceptions of the public provision of TOP procedures offer an explanation as to why there is a gap between the Choice Act and its satisfactory implementation. The TOP system is essentially poorly equipped to meet the physical and emotional needs of women seeking TOP services. The provision of TOP services is shaped by negative personal views and obstructionist attitudes from within the medical profession and the broader community.

Since the introduction of the Choice Act, the state has failed actively to engage its constitutional responsibility to continually revise and adjust its TOP implementation policy to bring it in line with changes in demand and with societal trends. This far-reaching inaction allows for obstructionist behaviour

185 Ibid.

186 Mamabolo \& Tjallinks (note 62 above) 82. The authors do not mention values-clarification workshops specifically, but, instead, suggest that adequate counselling and psychological support will place providers in a better position to perform their responsibilities adequately.

187 The Choice Act s 10(1)(c) penalises interference with access to TOP to the extent that any person who is found to have prevented a lawful TOP procedure, or obstructed access to a TOP facility, is guilty of an offence. However, there is no known case law indicating that this specific provision has been relied on before a criminal court. 
to remain unchecked and results in the Choice Act being implemented inconsistently and ineffectively. Further, all role-players avoid accountability. The state is required to adopt a leadership role and to provide clear direction concerning policy implementation plans, plans which can best be realised by using women's experiences as the starting point. In addition to improving access to broader reproductive health care and education, values-clarification workshops hold the key to addressing systemic and deeply rooted divides between TOP 'need' and TOP 'opposition'.

Social-support structures need to build a bridge linking women in need to the benefits of the Choice Act. As long as the conditions mentioned here persist, the quality of care will be compromised and women will be at risk of having their right to access safe TOP services violated and their health compromised. It is not enough that 'at least it gets done', and it is unacceptable that it 'gets done' under the conditions described in this article. The Choice Act must be understood and evaluated in its clinical application in order for any reform to be meaningful. 